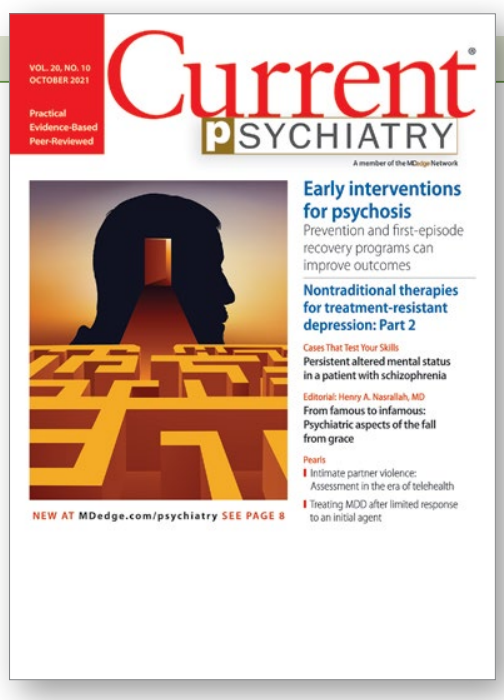

October 2021

\section{The perils of hubris}

Dr. Nasrallah's fascinating editorial on the psychiatric aspects of prominent individuals' fall from grace ("From famous to infamous: Psychiatric aspects of the fall from grace," From the Editor, Current Psychiatry, October 2021, p. 9-10,53) reminded me that the most trenchant insights and antidotes to hubris can more often be found in literature than in a diagnostic code. In Bonfire of the Vanities, ${ }^{1}$ Tom's Wolfe's satire on 1980s New York, self-proclaimed "Master of the Universe" Sherman McCoy lives in a Park Avenue high rise and works as a bond trader "on Wall Street, fifty floors up ... overlooking the world!" As quickly becomes apparent, Sherman's altitude-both literal and figurative-merely serves as a greater distance from which to fall.

\section{Keep in touch!}

OR

Comments \& Controversies

CURRENT PSYCHITRY

7 Century Drive, Suite 302

Parsippany, NJ 07054

All letters are subject to editing.
Perhaps fittingly, the phenomenon of self-destruction as a byproduct of success was most prominently "diagnosed" by business school professors, not physicians. The propensity for ethical failure at the apex of achievement was coined the "Bathsheba Syndrome," in reference to the biblical tale of King David's degenerative sequence of temptation, infidelity, deceit, and treachery while at the height of his power.' David's transgressions are enabled by the very success he has achieved. ${ }^{3}$

One of my valued mentors had an interesting, albeit unscientific, method of mitigating hubris. When he was a senior military lawyer, or judge advocate (JAG), and I was a junior one, my mentor took me to a briefing in which he provided a legal overview to newly minted colonels assuming command billets. One of the functions of JAGs is to provide counsel and advice to commanders. As Dr. Nasrallah noted in his editorial, military leaders are by no means immune from the proverbial fall from grace, and arguably particularly susceptible to it. In beginning his remarks, my mentor offered his heartfelt congratulations to the attendees on their promotion and then proceeded to hand out a pocket mirror for them to pass around. He asked each officer to look in the mirror and personally confirm for him that they were just as unattractive today as they were yesterday.

Charles G. Kels, JD Defense Health Agency San Antonio, Texas

The views expressed in this letter are those of the author and do not necessarily reflect those of any government agency.

References

1. Wolfe T. Bonfire of the vanities. Farrar, Straus and Giroux; 1987.
2. Ludwig DC, Longenecker CO. The Bathsheba syndrome: the ethical failure of successful leaders. J Bus Ethics. 1993;12:265-273

3. 2 Samuel 11-12.

I enjoyed Dr. Nasrallah's editorial and his discussion of the dangers of hubris. This brought to mind the role of the auriga in ancient Rome: "the auriga was a slave with gladiator status, whose duty it was to drive a biga, the light vehicle powered by two horses, to transport some important Romans, mainly duces (military commanders). An auriga was a sort of "chauffeur" for important men and was carefully selected from among trustworthy slaves only. It has been supposed also that this name was given to the slave who held a laurel crown, during Roman Triumphs, over the head of the dux, standing at his back but continuously whispering in his ears "Memento Mori" ("remember you are mortal") to prevent the celebrated commander from losing his sense of proportion in the excesses of the celebrations." ${ }^{1}$

Mark S. Komrad, MD Faculty of Psychiatry Johns Hopkins Hospital University of Maryland Tulane University Towson, Maryland

\section{Reference}

1. Auriga (slave). Accessed November 9, 2021. https://en.wikipedia.org/wiki/Auriga_(slave)

\section{Barriers to care faced by African American patients}

According to the US Department of Health and Human Services, the 5 domains of social determinants of health are Economic Stability, Education Access and Quality, Health Care Access and Quality, Neighborhood and Built Environment, and Social and Community Context. ${ }^{1}$ Patients who are African American 
face many socioeconomic barriers to access to psychiatric care, including economic inequality, inadequate knowledge about mental health, and deficient social environments. These barriers have a significant impact on the accessibility of psychiatric health care within this community, and they need to be addressed.

Jegede et $\mathrm{al}^{2}$ discussed how financial woes and insecurity within the African American community contribute to health care inequalities and adverse health outcomes. According to the US Census Bureau, in 2020, compared to other ethnic groups, African American individuals had the lowest median income. ${ }^{3}$ Alang $^{4}$ discussed how the stigma of mental health was a barrier among younger, college-educated individuals who are African American, and that those with higher education were more likely to minimize and report low treatment effectiveness. As clinicians, we often fail to discuss the effects the perceived social and cultural stigma of being diagnosed with a substance use or mental health disorder has on seeking care, treatment, and therapy by African American patients. The stigma of being judged by family members or the community and being seen as "weak" for seeking treatment has a detrimental impact on access to psychiatric care. ${ }^{2}$ It is our duty as clinicians to understand these kinds of stigmas and seek ways to mitigate them within this community.

Also, we must not underestimate the importance of patients having access to transportation to treatment. We know that social support is integral to treatment, recovery, and relapse prevention. Chronic cycles of treatment and relapse can occur due to inadequate social support. Having access to a reliable driver-especially one who is a family member or member of the community-can be vital to establishing social support. Jegede et $\mathrm{al}^{2}$ found that access to adequate transportation has proven therapeutic benefits and lessens the risk of relapse with decreased exposure to risky environments. We need to devise solutions to help patients find adequate and reliable transportation.

Clinicians should be culturally mindful and aware of the barriers to psychiatric care faced by patients who are African American. They should understand the importance of removing these barriers, and work to improve this population's access to psychiatric care. Though this may be a daunting task that requires considerable time and resources, as health care providers, we can start the process by communicating and working with local politicians and community leaders. By working together, we can develop a plan to combat these socioeconomic barriers and provide access to psychiatric care within the African American community.

Craig Perry, MD

Elohor Otite, MD

Stacy Doumas, MD

Jersey Shore University Medical Center Neptune, New Jersey

References

1. Healthy People 2030, US Department of Health and Human Services, Office of Disease Prevention and Health Promotion. Social determinants of health. Accessed November 9, 2021. https:// health.gov/healthypeople/objectives-and-data/ social-determinants-health

2. Jegede O, Muvvala S, Katehis E, et al. Perceived barriers to access care, anticipated discrimination and structural vulnerability among African Americans with substance use disorders. Int J Soc Psychiatry. 2021;67(2):136-143.

3. Shrider EA, Kollar M, Chen F, et al. US Census Bureau, Current Population Reports, P60-273, Income and Poverty in the United States: 2020. US Government Publishing Office; 2021.

4. Alang SM. Mental health care among blacks in America: confronting racism and constructing solutions. Health Serv Res. 2019;54(2):346-355.

Disclosures

The authors report no financial relationships with any companies whose products are mentioned in their letters, or with manufacturers of competing products.

doi: 10.12788/cp.0198 